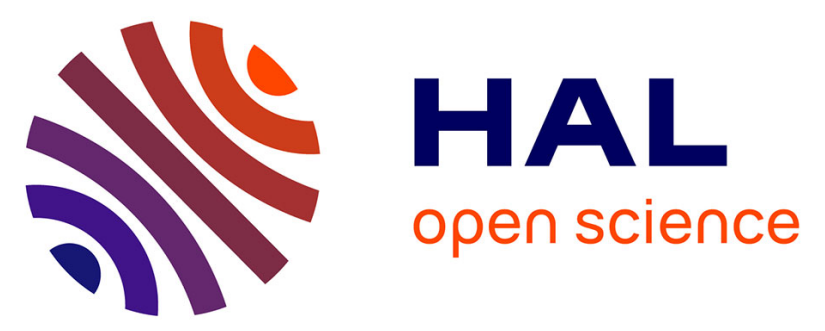

\title{
2,3,7,8-Tetrachlorodibenzo-p-Dioxin Counteracts the p53 Response to a Genotoxicant by Upregulating Expression of the Metastasis Marker AGR2 in the Hepatocarcinoma Cell Line HepG2
}

\author{
Ariane Ambolet-Camoit, Linh Chi Bui, Stéphane Pierre, Aline Chevallier, \\ Alexandre Marchand, Xavier Coumoul, Michèle Garlatti, Karine Andreau, \\ Robert Barouki, Martine Aggerbeck
}

\section{To cite this version:}

Ariane Ambolet-Camoit, Linh Chi Bui, Stéphane Pierre, Aline Chevallier, Alexandre Marchand, et al.. 2,3,7,8-Tetrachlorodibenzo-p-Dioxin Counteracts the p53 Response to a Genotoxicant by Upregulating Expression of the Metastasis Marker AGR2 in the Hepatocarcinoma Cell Line HepG2. Toxicological Sciences, 2010, 115 (2), pp.501-512. 10.1093/toxsci/kfq082 . hal-02190079

\author{
HAL Id: hal-02190079 \\ https://hal.science/hal-02190079
}

Submitted on 21 Jul 2019

HAL is a multi-disciplinary open access archive for the deposit and dissemination of scientific research documents, whether they are published or not. The documents may come from teaching and research institutions in France or abroad, or from public or private research centers.
L'archive ouverte pluridisciplinaire HAL, est destinée au dépôt et à la diffusion de documents scientifiques de niveau recherche, publiés ou non, émanant des établissements d'enseignement et de recherche français ou étrangers, des laboratoires publics ou privés. 


\section{2,3,7,8-Tetrachlorodibenzo- $p$-Dioxin counteracts the p53 response to a}

\section{genotoxicant by up-regulating expression of the metastasis marker AGR2}

\section{in the hepatocarcinoma cell line HepG2}

Ariane Ambolet-Camoit ${ }^{*}$, , Linh Chi Bui ${ }^{*}, \dagger$, Stéphane Pierre ${ }^{*}, \dagger$, Aline Chevallier ${ }^{*}, \dagger$, Alexandre

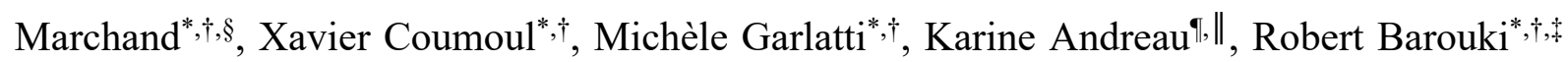
and Martine Aggerbeck ${ }^{*} \dagger$

${ }^{*}$ INSERM UMR-S 747, 75006 Paris, France

${ }^{\dagger}$ Université Paris Descartes, Centre Universitaire des Saints-Pères, 75006 Paris, France

¥APHP, Hôpital Necker Enfants Malades, Service de Biochimie Métabolique, Paris, 75015

France

§ Present address: INSERM UMR-S 956, 75013 Paris, France

" Unité de Biologie Fonctionnelle et Adaptative (BFA), EAC CNRS 4413, 75013 Paris, France

\| Université Paris 7, Denis Diderot, 75013 Paris, France

Corresponding author: Dr Martine Aggerbeck, UMR-S 747 INSERM, Toxicologie, Pharmacologie et Signalisation Cellulaire, Université Paris Descartes, Centre Universitaire des Saints-Pères, 45 rue des Saints-Pères, 75006 Paris, France

Tel : (33) $142862093 \quad$ Fax : (33) 142863868

e-mail : martine.aggerbeck@parisdescartes.fr

email-addresses: ariane.ambolet@parisdescartes.fr; linh-chi.bui@univ-paris5.fr; stephane.pierre@univ-paris5.fr; aline.chevallier@parisdescartes.fr; alexandre.marchand@upmc.fr; xavier.coumoul@parisdescartes.fr; michele.garlatti@univparis5.fr; karine.andreau@univ-paris-diderot.fr; robert.barouki@parisdescartes.fr; martine.aggerbeck@parisdescartes.fr

Short title: TCDD-regulated AGR2 inhibits etoposide effect 


\section{Abstract and keywords}

TCDD (2,3,7,8-tetrachlorodibenzo-p-dioxin) is an environmental pollutant which binds the aryl hydrocarbon receptor (AhR), a transcription factor that triggers various biological responses. In this study, we show that TCDD treatment counteracts the p53 activation elicited by a genotoxic compound, etoposide, in the human hepatocarcinoma cell line HepG2 and we delineated the mechanisms of this interaction. Using siRNA knock-down experiments, we found that the newly described metastasis marker, anterior gradient-2 (AGR2), is involved in this effect. Both AGR2 mRNA and protein levels were increased (6and 4-fold, respectively) by TCDD treatment and this effect was mediated by the AhR receptor. The half-life of AGR2 mRNA was unchanged by TCDD treatment. Analysis of the promoter of the AGR2 gene revealed 3 putative xenobiotic responsive elements (XRE) in the proximal $3.5 \mathrm{~kb}$ promoter. Transient transfection of HepG2 cells by the Gaussia luciferase reporter gene driven by various deleted and mutated fragments of the promoter indicated that only the most proximal XRE was active. These results suggest that AhR ligands such as TCDD may contribute to tumour progression by inhibiting p53 regulation by genotoxicants via the increased expression of the metastasis marker AGR2.

Keywords: AGR2, TCDD, AhR, etoposide, p53 


\section{Introduction}

Delineating the effects of combinations of toxicants (cocktail effects) is one of the most challenging issues in current toxicology. Since humans and multiple ecosystems are exposed to hundreds of pollutants, risk assessment should take into consideration the possible interactions among those chemicals. This is clearly impractical for all the possible combinations. However, one feasible approach would be to define the major signalling pathways activated by toxic compounds and to assess the interactions among those pathways using representative activators. In the present study we focused on the interaction between a genotoxic compound, etoposide, and a cancer-promoting non-genotoxic pollutant, TCDD, and we found that AGR2 inhibits the post-translational modifications of the p53 protein elicited by etoposide.

TCDD (TCDD, 2,3,7,8-tetrachlorodibenzo-p-dioxin) is a ubiquitous chemical in the environment which accumulates in animal and human tissues. TCDD has been classified as a group 1 human carcinogen by the International Agency for Research on Cancer and as likely to be carcinogenic to humans by the Environmental Protection Agency in the United States because it is suspected to play a role in cancer development $\{$ Kaiser, $2000 \# 43$ \}. Most TCDD effects are mediated by the aryl hydrocarbon receptor (AhR) $\{\mathrm{Gu}, 2000 \# 19\}$. Upon binding to its ligands, cytoplasmic AhR, which is bound to several chaperone proteins \{Petrulis, 2002 \#20; Ramadoss, $2005 \# 24$ \}, undergoes a conformational change that leads to its dissociation from the chaperone proteins and its translocation into the nucleus where it dimerizes with its partner Arnt (AhR receptor nuclear translocator $\{$ Swanson, $2002 \# 21\}$ ). The heterodimer binds to Xenobiotic Responsive Elements in the promoters of target genes resulting in the upregulation of these genes. TCDD is well known for up-regulating the genes encoding the enzymes involved in the metabolism of xenobiotics, such as cytochrome P450 (CYP) 1A1 
$\{\mathrm{Xu}, 2005 \# 22\}$. However, a growing body of literature indicates that the AhR controls the expression of a wide variety of genes that are unrelated to the metabolism of xenobiotics (reviewed in $\{$ Kung, $2009 \# 46\}$ ).

Etoposide is an antineoplastic compound which inhibits topoisomerase II activity thus leading to single strand DNA breaks and p53 activation. Previous studies have shown that TCDD attenuates the p53 response to DNA damaging agents in HepG2 cells \{Paajarvi, 2005 $\# 28$. In human keratinocytes, TCDD was shown to attenuate senescence and repress p53 expression leading to immortalization of the cells \{Ray, $2004 \# 44\}$. In AhR-/- fibroblasts transfected with the AhR under TET-OFF control, AhR activation inhibits E2F1-induced apoptosis $\{$ Marlowe, $2008 \# 60$ \}. Although cross-talk between the apoptosis/cell cycle pathways and the AhR signalling pathway has been described (see \{Puga, $2009 \# 54$ \} for review), this appears to be a species- or cell type-dependent phenomena \{Marlowe, 2005 $\# 55$ \} and the molecular mechanisms are only partially understood.

We hypothesized that the interaction between the TCDD/AhR pathway and the p53 pathway could be mediated through the product of an AhR-target gene. Recent high throughput analyses of TCDD-regulated gene expression in HepG2 cells have revealed novel targets for this pollutant which may account for some features of its toxicity \{Frueh, 2001 \#13; Kim, 2006 \#15; Puga, 2000 \#14\}. In particular, the regulation of several genes involved in cell motility may account for the toxicity of TCDD observed during development and for its effects on genes promoting cancer progression $\{$ Diry, $2006 \# 2\}$. For the purposes of this study, we focused on the anterior gradient 2 (AGR2) gene because previous studies showed that overexpression of AGR2 attenuates p53 serine phosphorylation \{Pohler, $2004 \# 18\}$. Our microarray analyses have revealed a 10-fold increase of AGR2 gene expression in HepG2 cells following 30 hours of treatment with $25 \mathrm{nM}$ TCDD (A. Marchand \& M. Garlatti, unpublished results). Human AGR2, also designated as hAG2 and as GOB-4 in the mouse 
\{Komiya, $1999 \# 57\}$, are orthologues of the secreted Xenopus laevis protein (XAG-2) \{Aberger, $1998 \# 11\}$. In this species, the protein is involved in the differentiation of the mucus-secreting cement gland and the pattern of anterior neural tissues. In humans, AGR2 expression is increased in various cancers $\{$ Innes, 2006 \#5; Zhang, $2005 \# 8\}$ and, recently, the protein was suggested to be a potential oncogene in lung cancer \{Fritzsche, 2007 \#3; Zhu, $2007 \# 17\}$. In addition, overexpression of AGR2 silences p53 activity in UV-exposed lung cancer cells $\{$ Pohler, $2004 \# 18\}$. In the present study, we found that TCDD treatment increased AGR2 protein and mRNA levels and elicited an AhR-mediated activation of the AGR2 gene promoter. We also show that TCDD attenuates p53 phosphorylation and acetylation as well as caspases $3 / 7$ activation by etoposide and, using siRNA knock down experiments, that these effects of TCDD are mediated by the up-regulation of AGR2. Thus, AGR2 appears as a novel participant involved in the interaction between the TCDD/AhR pathway and the etoposide/p53 pathway in HepG2 cells. 


\section{Material and methods}

Cell culture and chemicals. The human hepatocarcinoma cell line HepG2, obtained from the ATCC (\# HB-8065), was cultured as described previously \{Bui, $2009 \# 58\}$. TCDD was purchased from Promochem (Molsheim, France). Benzo(a)pyrene (B(a)P) and etoposide were from Sigma-Aldrich (France). DMSO 0.15\% (Merck) was used as a control. Oligonucleotides were purchased from Operon or Eurogentec (France).

RNA preparation. For most experiments, 0.4 million cells were seeded into 6-well plates and treated, or not, 2 days later with the compounds indicated in the figures. RNA was prepared using the RNeasy mini kit from Qiagen (France) as described $\{$ Bui, $2009 \# 58$ \}.

Quantitative reverse transcriptase PCR. Reverse transcription was performed using the High Capacity cDNA reverse transcription kit (Applied Biosystems, France) as described \{Bui, $2009 \# 58$ \}. cDNAs were aliquoted and stored at $-80^{\circ} \mathrm{C}$. Quantitative PCR was performed with $40 \mathrm{ng}$ of cDNA as described previously \{Bui, $2009 \# 58$ \}. The AGR2 and reference gene RPL13A, a ribosomal gene mRNA, amounts were measured. The primers were: AGR2 forward 5'-GCCATCAGGAGAAAGGTG-3' and reverse 5'GCCAAAAAGGACACAAAGG-3'; RPL13A forward 5'CCTGGAGGAGAAGAGGAAAGAGA-3, and 5'GAGGACCTCTGTGTATTTGTCAA-3’.

Cellular protein extracts. Proteins were prepared from cells seeded under the same conditions as for the mRNA experiments. The cells were washed twice with PBS and scraped into $200 \mu \mathrm{L}$ of M-Per buffer (Pierce, France) containing $0.15 \mathrm{M} \mathrm{NaCl}$, protease and phosphatase inhibitors (Sigma). The cellular homogenate was centrifuged $15 \mathrm{~min}$ at 12000 
rpm at $4{ }^{\circ} \mathrm{C}$. The protein concentration was measured by the $\mathrm{BCA}$ method (Pierce) using bovine serum albumin (fraction $\mathrm{V}$ ) as a standard. The protein extract was stored at $-80^{\circ} \mathrm{C}$.

Western blots. Samples $(20-40 \mu \mathrm{g}$ of extract) and $8 \mu \mathrm{g}$ of protein ladder (Fermentas, France) were electrophoresed in a $15 \%$ or $12 \%$ polyacrylamide, $0.1 \%$ SDS gel. Proteins were transferred onto nitrocellulose Hybond C extra membranes (GE Healthcare, France). Blots were incubated for $120 \mathrm{~min}$ in $0.2 \%$ I-Block solution (Applied Biosystems, France), 0.1\% Tween-20 in 1X PBS at room temperature. Primary antibodies (anti AGR2, Abnova, 1/1000, anti phospho p53 (Ser15), Cell Signaling, 1/1000, anti acetylated p53 (lys382), Abcam, 1/1000, anti p53, Cell Signaling, 1/1000 or anti actin, Abcam, 1/20 000, France, anti AhR (ab2770), Abcam, 1/1000) were incubated overnight at $4^{\circ} \mathrm{C}$ and rinsed 5 times $(5 \mathrm{~min})$ with $0.1 \%$ Tween-20 in $1 \mathrm{X}$ PBS at room temperature. Signals were visualized and quantification was carried out as previously described using actin to normalize the signals $\{$ Bui, $2009 \# 58\}$.

mRNA stabilty. HepG2 cells were treated with either the vehicle (0.15\% DMSO) or $25 \mathrm{nM}$ TCDD for 30 hours. DRB (5,6-dichloro-1 $\beta$-ribofuranosyl benzimidazole, Sigma-Aldrich) (10 $\mu \mathrm{M})$ was then added to the cells and mRNA was prepared at various times after this addition.

Plasmids and transient transfections. Fragments of the AGR2 gene promoter were obtained by PCR and subcloned into the TOPO TA cloning vector (Invitrogen, France). Plasmids were prepared (QIAprep spin miniprep kit, Qiagen, France) and, after DNA digestion, the promoter fragment was cloned into the pGLuc vector (Biolabs, Ozyme, France). Mutagenesis was performed using the Quick Change ${ }^{\circledR}$ XL site-directed mutagenesis kit from Stratagene (France). The PCR products were purified (mini elute PCR purification kit, Qiagen) and 
cloned in the pGLuc vector as described above. Mutations were verified by DNA sequencing (GATC, France).

HepG2 cells ( 0.4 million cells/well of 6-well plates) were transiently transfected in duplicate or triplicate by the lipofectamine-2000 reagent, using $1 \mu \mathrm{g}$ DNA/well, according to the manufacturer's instructions (Invitrogen, France). Sixteen hours later, fresh medium containing the compounds was added to the cells for 30 hours. The Gaussia luciferase activity was assayed with the Biolabs kit (Ozyme, France) according to in a Berthold luminometer.

Chromatin ImmunoPrecipitation assay. The detailed protocole is provided as supplementary information (S1).

Nuclear extract preparation and electrophoretic mobility shift assay. The detailed protocole is provided as supplementary information (S2).

AhR and AGR2 gene silencing. HepG2 cells (0.4 million cells/well in 6-well plates) were transfected with $5 \mathrm{nM}$ of either control siRNA or 2 different siAhR (Qiagen, France) using HiPerfect transfection reagent according to the manufacturer's protocol (Qiagen) as described \{Bui, $2009 \# 58\}$. After 12 hours, the medium was replaced by fresh medium and 16 hours later the cells were treated, or not, with $25 \mathrm{nM}$ TCDD for an additional 30 hours. Control siRNA was a custom GFP siRNA (ref 1027020), siAhR1 was the fluorescent Hs_AHR_5_HP validated siRNA (ref SI02780148) and siAhR2 was the Hs_AHR_6_HP validated siRNA (ref SI03043971).

For siAGR2 experiments, HepG2 cells were transfected using the "Fast-Forward Protocol" (Qiagen). HepG2 cells were seeded and transfected simultaneously with $5 \mathrm{nM}$ of either control siRNA (ref SR-CL000-005, Eurogentec) or siAGR2 (ref SI00293447, Qiagen), 
using HiPerfect transfection reagent. After 16 hours, the cells were treated with either $0.15 \%$ DMSO or $25 \mathrm{nM}$ TCDD. Twenty-four hours later, the cells were treated, or not, with either 15 or $75 \mu \mathrm{M}$ etoposide and DMSO or TCDD for an additional 24 hours.

Caspases 3/7 activities assay. HepG2 cells (5000 cells/well in 96-well plates) were seeded and transfected, or not, with control siRNA or siAGR2 in triplicate. Cells were treated as described above in "AhR and AGR2 gene silencing". After a 48 hour treatment, $100 \mu \mathrm{L}$ of fresh medium and $100 \mu \mathrm{L}$ of Caspase-Glo ${ }^{\circledR}$ 3/7 reagent (Promega) were added to each well. After 90 min incubation at room temperature, the luminescence was measured in a platereading luminometer (ENVision 2101 Multi-label Reader, Perkin Elmer).

XTT assay. HepG2 cells (10,000 cells/well in 96-well plates) were seeded and treated or not for 24 hours by $25 \mathrm{nM}$ TCDD prior to the treatment for an additional 24 or 48 hours by various concentrations of etoposide or DMSO. Cell viability was measured by the XTT test following the manufacturer's instructions (In Cytotox XTT, Xenometrix, Biogenic, France).

Statistical analysis. The data (mean \pm SEM) were obtained from at least three different experiments. A Kruskal-Wallis test (non parametric comparison of $\mathrm{k}$ independent series) was followed by an ANOVA test (parametric comparison of $\mathrm{k}$ independent series, Fisher-test). A value of $\mathrm{P}<0.05$ or less was accepted as being statistically significant. 


\section{Results}

\section{Interaction between TCDD and etoposide treatments}

Treatment of HepG2 cells with etoposide led to the activation of p53 as demonstrated by an increased phosphorylation of serine 15 (figure 1A) and by an increased acetylation of lysine 382 (figure 1B). Under these experimental conditions, the total amount of p53 was increased by etoposide treatment as already described by Pääjärvi and collaborators \{Paajarvi, $2005 \# 28$ \} (figure 1A). p53 activation may initiate either apoptosis or cell cycle arrest and, ultimately, senescence, depending on the severity of the damage $\{$ Kruse, $2009 \# 56\}$. We, therefore, investigated the regulation of the effector caspases $3 / 7$, following the same treatment. As shown in figure $1 \mathrm{C}$, etoposide treatment increased the caspases $3 / 7$ activities. When combined with etoposide, TCDD prevented, partially, the increases in p53 phosphorylation and acetylation and caspases $3 / 7$ activities by the genotoxic agent, whereas TCDD alone had no effect (figures 1A, B, C). These experiments show that the distinct signalling pathways activated by these two toxicants interact at the level of the p53 protein hub. We tested if the combination of etoposide and TCDD modified the viability of the cells as compared to each compound alone, by measuring the mitochondrial succinate dehydrogenase activity. As shown in figure 1D, TCDD moderately increased the enzyme activity as compared to the vehicule DMSO. As expected, etoposide treatment led to a decreased activity which was partially rescued when the cells were treated by the combination of etoposide and TCDD.

In order to determine the mechanism of this cross-talk, we analyzed the gene targets of TCDD as revealed by our microarray data and we found that the AGR2 gene, which has previously been shown to counteract p53 activation \{Pohler, $2004 \# 18$, was one of the putative targets of TCDD in HepG2 cells ( $\{$ Marchand, 2005 \#1\}, A. Marchand \& M. Garlatti, 
unpublished data). We, therefore, investigated the regulation of the AGR2 gene by TCDD in order to establish its role in the etoposide-TCDD interaction.

\section{TCDD increases AGR2 mRNA and protein expression in HepG2 cells}

HepG2 cells were treated with vehicle alone $(0.15 \%$ DMSO) or with $25 \mathrm{nM}$ TCDD within the concentration range typically used for experiments with human cells $(5-100 \mathrm{nM})$. RNA levels were monitored by quantitative real time PCR (qRT-PCR). As shown in figure 2A, a 6-fold increase in RNA levels was found after 30h of TCDD treatment. The increase in the amount of mRNA first became significant at $8 \mathrm{~h}$ and remained stable between $30 \mathrm{~h}$ and $72 \mathrm{~h}$ (figure 2A). A 60-fold increase of the amount of mRNA for the classical AhR target gene, CYP1A1 was found as early as $4 \mathrm{~h}$ and a 200 -fold increase leveled as early as $12 \mathrm{~h}$ (data not shown).

The amount of AGR2 protein after treatment, as measured by Western blot analysis, also increased in cellular extracts of HepG2 cells treated for $8 \mathrm{~h}$ to $72 \mathrm{~h}$ with $25 \mathrm{nM}$ TCDD as compared to the vehicle. A typical western blot is shown in figure 2B. Quantification showed a statistically significant 3 - to 4-fold increase of the AGR2 protein level in cellular extracts following $24 \mathrm{~h}$ to $72 \mathrm{~h}$ of TCDD exposure (figure $2 \mathrm{C}$ ).

\section{TCDD regulation of AGR2 involves the AhR}

Since most TCDD effects are mediated by its receptor, AhR, we investigated the effects of another ligand of the AhR. As shown in figure 3A, benzo(a)pyrene was as potent as TCDD in increasing AGR2 protein levels after 30h of treatment (4-fold increase).

To further assess the role of the AhR in the regulation of AGR2 gene expression by TCDD, we used targeted gene silencing. We verified that the AhR and AGR2 protein expression was inhibited with specific AhR-targeted small interfering RNA (figure 3B, right). 
Figure 3B (left) shows the effect of AhR siRNA on the increase in AGR2 mRNA levels elicited by TCDD. Transfection of the control siRNA did not modify the up-regulation of AGR2 expression by TCDD. However, a statistically significant $75 \%$ decrease of the TCDD response was observed when AhR-targeted siRNAs were transfected. Together, these results clearly demonstrate the involvement of the AhR in the regulation of AGR2 by TCDD.

\section{AGR2 mRNA stability is not modified by TCDD treatment}

In order to discriminate between an effect of TCDD on AGR2 mRNA transcription or stability, we measured the AGR2 half-life in HepG2 cells treated, or not, by TCDD. For this purpose, after a $30 \mathrm{~h}$ pretreatment by TCDD, the cells were treated with 5,6-dichloro-1 $\beta$ ribofuranosyl benzimidazole (DRB), a RNA polymerase II inhibitor. The amount of AGR2 mRNA was measured as a function of time. In both control and TCDD-treated HepG2 cells, mRNA levels declined with half-lives of $20 \mathrm{~h}$ and $26 \mathrm{~h}$, respectively, with no statistical difference between the 2 groups (figure 4). In cells treated with either DMSO or TCDD in the absence of DRB, the mRNA level remained unchanged (data not shown). Hence, TCDD did not alter mRNA stability and its effect was likely transcriptional.

\section{TCDD-induced activation of AGR2 is mediated at the transcriptional level}

To elucidate the transcriptional nature of the TCDD effect, transfection experiments were performed following promoter sequence analysis. Three putative XREs were found in the proximal 4000 bp promoter by MatInspector ${ }^{\circledR}$ analysis. Deletions of the AGR2 gene promoter were introduced into a basic expression vector upstream of the Gaussia luciferase, a reporter enzyme secreted into the medium of the cell culture. These constructs were transiently transfected into HepG2 cells to analyze the putative functional XRE(s) involved in the regulation of the AGR2 gene by AhR agonists. The cells were treated with TCDD or the 
vehicle and the luciferase activity released into the culture medium was measured. As expected, TCDD had no effect on the empty plasmid and the basal activity was low $(0.3$ arbitrary units). In contrast, all the AGR2 constructs tested displayed a higher basal activity (2 to 4 arbitrary units) and a 2- to 5-fold increase following treatment with $25 \mathrm{nM}$ TCDD was observed for the constructs tested (figure 5A). Deletion of XRE3 did not modify the regulation of the reporter gene by dioxin.

In order to determine which XREs were responsible for the induction by TCDD of the luciferase activity, XREs 1 and 2 were mutated. As shown in figure 5A, the mutation of the proximal XRE (XRE1) completely abolished the effect of TCDD on the regulation of the AGR2 promoter whereas the mutation in XRE2 did not modify the reporter activity. Chromatin immunoprecipitation experiments demonstrated that treatment for 45 min with TCDD stimulated AhR recruitment to the region of the AGR2 promoter that encompasses XRE1 (figure 5B, left). Moreover, electrophoretic mobility shift assay experiments revealed a specific band when a probe encompassing XRE1 was incubated with nuclear extracts prepared from TCDD-treated HepG2 cells. This band was displaced by competition with a 50-fold excess of cold probe and was partially decreased when an anti-AhR antibody was used (figure 5B, right).

A dose response curve was performed to determine the responsiveness of the longest AGR2 construct (pGLuc AGR2 -3401/+8) to TCDD. A significant increase of the Gaussia luciferase activity was obtained at a concentration as low as 1nM TCDD and up to $50 \mathrm{nM}$ TCDD (figure 5C). Another AhR ligand, benzo(a)pyrene, was as effective as TCDD (4-fold increase) in increasing the reporter activity of this construct (figure 5C).

\section{TCDD attenuation of etoposide action is mediated by AGR2}


As shown in fig 1A, etoposide treatment induced phosphorylation of Ser15 and acetylation of Lys382 in p53. Pre-treatment with TCDD partially prevented these modifications of p53 by etoposide. In order to determine whether AGR2 was involved in the TCDD effect, HepG2 cells were transfected with either control siRNA or AGR2 siRNA prior to the treatments. AGR2 siRNA transfection significantly decreased AGR2 mRNA levels of both untreated or TCDD-treated cells (75 to $80 \%$ decrease, data not shown). A significant 40\% decrease in AGR2 protein levels was also observed whereas control siRNA had no effect under the same conditions (figure 6A). In AGR2-silenced cells, the inhibitory effect of TCDD on p53 phosphorylation (serine 15) and acetylation (lysine 382) was abolished whereas control siRNA treated cells were still responsive to TCDD (figures 6A and B). This indicates that the attenuation of p53 activation by TCDD was dependent, at least in part, on AGR2 expression. We also investigated the role of AGR2 expression on the effector caspases 3/7 activities. As shown in figure $6 \mathrm{C}$, when the cells were transfected by the control siRNA, pretreatment by TCDD led to a statistically significant $50 \%$ decrease of the effect of etoposide on caspases $3 / 7$ activities. The negative effect of TCDD on etoposide activation of caspases 3/7 was considerably reduced in the presence of AGR2 siRNA. 


\section{Discussion}

In this paper, we report a cross-talk mechanism between etoposide, a genotoxicant which is a potent activator of the p53 pathway, and TCDD, a tumor promoter which activates the AhR pathway in the hepatocyte-derived cell line HepG2. In particular, pretreatment of HepG2 cells by TCDD partially counteracts activation of p53 induced by etoposide. The finding that the human anterior gradient 2 (AGR2) silences p53 response to DNA damage \{Pohler, $2004 \# 18\}$ and our transcriptomic results showing that TCDD regulates AGR2 mRNA levels in the same cellular model (A. Marchand \& M. Garlatti, personal data) led us to hypothesize that this new TCDD target could be partially responsible for some of the TCDD effects on p53 regulation, as proposed in figure 7 . Therefore, we characterized the positive regulation, by TCDD, of the gene encoding the human anterior gradient 2 and showed that TCDD attenuates etoposide-mediated p53 phosphorylation and acetylation through AGR2 gene regulation.

Induction of AGR2 by TCDD could have several consequences. One hypothesis is that induction of AGR2 by TCDD, which is a recognized carcinogen, or other AhR ligands could promote tumor formation. Indeed, recently, AGR2 was shown to be over-expressed in several human cancers - prostate, pancreas, lung and breast cancer \{ Fritzsche, 2007 \#3; Fritzsche, 2006 \#6; Innes, 2006 \#5; Missiaglia, 2004 \#48; Ramachandran, 2008 \#33; Sitek, 2009 \#47; Thompson, 1998 \#10; Wang, 2008 \#35; Zhang, 2005 \#8; Zheng, 2006 \#34\}. AGR2 also has been proposed as a novel putative metastasis marker in breast, prostate and colorectal cancer \{Fletcher, 2003 \#9; Smirnov, 2005 \#16; Liu, 2005 \#7; Thompson, 1998 \#10\}, and it is associated with poor survival of prostate cancer patients \{Zhang, $2007 \# 4\}$. Stable transfection of lung carcinoma H1299 cells by a vector expressing AGR2 was shown to enhance colony formation, an assay which measures the ability of a gene to influence cell survival. In another study, the oesophageal adenocarcinoma SEG-1 cell line displayed $82 \%$ 
fewer colonies in soft agar and smaller tumor xenografts when the AGR2 gene was silenced by sh-RNA as compared to wild-type cells $\{$ Wang, 2008 \#35\}. Furthermore, AGR2expressing NIH3T3 cells showed enhanced foci formation in soft agar and were able to grow as tumors in nude mice \{Wang, $2008 \# 35$ \}. Altogether, both in vivo and in vitro studies suggest that the expression of this new TCDD target correlates with a cancerous phenotype.

The data described here indicate that etoposide and TCDD elicit opposite effects on p53 regulation. The induction of AGR2 by TCDD suggests that the AGR2 gene product may account for the cross-talk between these toxicants which belong to two distinct classes. Indeed, the increase in caspases 3/7 activities and p53 phosphorylation and acetylation by etoposide is partially blunted by TCDD treatment and this effect appears to be correlated with AGR2 induction. Preliminary experiments indicate that constitutive overexpression of AGR2 in HepG2 cells inhibits the both the p53-phosphorylation on Ser15 and acetylation on Lys 382 in cells treated with etoposide (personal results). Thus, the combination of two toxicants with distinct mechanisms of action potentially could produce additional harmful effects that result from decreased adaptive pathways. It will now be of interest to study the effect of other pollutant combinations on p53 activity and AGR2 induction.

TCDD exposure leads to the activation of several gene targets involved in cell plasticity \{Bui, $2009 \# 58$; Diry, $2006 \# 2$ \}. Other results have shown that the AhR is involved in cell-cell or cell-substratum adhesion, thus this receptor might play a role in cell migration \{Barouki, 2007 \#40; Carvajal-Gonzalez, 2009 \#41\} and could have a major impact on cell adhesion and matrix metabolism $\{$ Kung, $2009 \# 46\}$. These new roles of the AhR suggest that it could have key functions in human cancer progression. Recent experiments have pointed out that AhR activation inhibits apoptosis triggered by UV light \{Chopra, 2009 \#59; Park, $2006 \# 51$ \}or by the E2F1 regulator of the cell cycle \{Marlowe, $2008 \# 60$ \} or by diethylnitrosamine $\{$ Paajarvi, $2005 \# 28$ \}. Culture induced senescence in keratinocytes is also 
suppress by TCDD or cigarette smoke $\{$ Ray, $2009 \# 45$; Zhang, $2007 \# 50\}$. Our finding that anterior gradient-2 is a novel target of the AhR which down-regulates p53 and caspases 3/7 activities elicited by a genotoxicant is another argument for the possible involvement of AhR in tumor progression..

It is noteworthy that AGR2 has been shown to be increased by different stress conditions, such as serum or oxygen depletion \{Zweitzig, $2007 \# 27\}$ or allergen exposure in asthma $\{$ Di Valentin, 2009 \#36\}. In addition, AGR2 expression is increased in the oesophageal Barrett's epithelium, a tissue which is subjected to various stresses such as acidbile reflux, heat shock and oxidative damage \{Pohler, $2004 \# 18\}$. Our study shows that AGR2 is also induced during xenobiotic stress. Thus, AGR2 appears to be a target frequently activated under stressful cellular conditions and it is possible that the combination of several stresses leading to AGR2 induction may result in additional toxic effects. Although little is known about anterior gradient-2 function in mammals, a protein disulfide isomerase (PDI) function is suspected, based on sequence homology \{Persson, $2005 \# 25$ \} and AGR2 could have a unique role in intestinal mucus production by forming disulfide bonds with mucin 2 \{Park, $2009 \# 26\}$. The fact that AGR2 is probably a member of the PDI chaperone family correlates with the fact that its expression is increased by a variety of stress conditions which require chaperone activity in the endoplasmic reticulum. However, other still unknown functions of AGR2 may also be important, for example, the fine tuning of p53 activity. Since AGR2 expression is correlated with cancer aggressiveness, it might constitute a worthwhile therapeutic target in the future if more extensive knowledge of its activity and of its regulation by hormones and chemicals is obtained. 


\section{Funding}

This work was supported by AFSSET (Agence Française de Sécurité Sanitaire de l'Environnement et du Travail); ANR (Agence Nationale de la Recherche 06SETS26, Oncopop); ARC (Association pour la Recherche sur le Cancer, 3927); INSERM (Institut National de la Santé et de la Recherche Médicale); Université Paris Descartes ; Ministère de l'Enseignement Supérieur et de la Recherche (Bourse doctorale, Ariane Ambolet-Camoit); Fondation pour la recherche Médicale (bourse post-doctorale, Lin-Chi Bui); Ligue contre le Cancer (bourse post-doctorale, Lin-Chi Bui) and Région Ile de France (Bourse doctorale, Stéphane Pierre).

\section{Acknowledgements}

We thank Dr L.P. Aggerbeck for critical reading of the manuscript. 


\section{References}




\section{Legends to figures}

Figure 1. Interaction between etoposide and TCDD on p53 phosphorylation and acetylation and caspases $3 / 7$ activities in HepG2 cells. A. HepG2 cells were pre-treated with either $0.15 \%$ DMSO or $25 \mathrm{nM}$ TCCD for $24 \mathrm{H}$ and incubated, or not, with $15 \mu \mathrm{M}$ etoposide for an additional $24 \mathrm{H}$. Western blot analysis was performed on protein extracts and p53 was identified with antibodies directed against total p53 or phospho-p53 (Ser15). Intensities were normalized by comparison to the actin signal ( 3 separate experiments). There was a statistically significant difference (Fisher-test) in p53 phosphorylation when the cells were treated with etoposide plus TCDD as compared to etoposide alone $(* P<0.05)$. B. HepG2 cells were pre-treated with either $0.15 \%$ DMSO or $25 \mathrm{nM}$ TCCD for $24 \mathrm{H}$ and incubated, or not, with $75 \mu \mathrm{M}$ etoposide for an additional $24 \mathrm{H}$. Western blot analysis was performed on protein extracts and p53 was identified with an antibody directed against acetylated-p53 (Lys 382). Intensities were normalized by comparison to the actin signal (4 separate experiments). There was a statistically significant difference (Fisher-test) in p53 acetylation when the cells were treated with etoposide plus TCDD as compared to etoposide alone $(* * P<0.001 ; * P<0.05)$. C. HepG2 cells were pre-treated with either $0.15 \%$ DMSO or $25 \mathrm{nM}$ TCDD for $24 \mathrm{H}$ and incubated, or not, with $75 \mu \mathrm{M}$ etoposide for an additional $24 \mathrm{H}$. There was a statistically significant increase (Fisher-test) in caspases 3/7 activities following etoposide treatment as compared to DMSO as well as a significant decrease following treatment with etoposide plus TCDD as compared to etoposide alone $\left(* P<0.05\right.$, ${ }^{* *} P<0.001$; $* * * P<0.0001)$.

Figure 2. TCDD increased AGR2 mRNA and protein levels in HepG2 cells. HepG2 cells were treated for various times with either $25 \mathrm{nM}$ TCDD or the vehicle $(0.15 \%$ DMSO). A. 
The AGR2 mRNA levels measured by qRT-PCR were normalized to the level obtained by treatment with the vehicle alone (4 to 19 experiments performed in duplicate). There was a significant increase (Fisher-test) in AGR2 mRNA levels after treatment with TCDD for $24 \mathrm{H}$ to $72 \mathrm{H}(* P<0.05 * * * P<0.0001)$. B. Proteins were analyzed by Western blot (anti-AGR2 monoclonal antibody). A typical western is shown. C. Quantification of the amount of AGR2 protein. Intensities were normalized by comparison to the actin signal (3 to 10 separate experiments). There was a significant increase in AGR2 protein (Fisher-test) following TCDD treatment for $24 \mathrm{H}$ to $48 \mathrm{H}(* P<0.02, * * * P<0.0001)$.

Figure 3. AGR2 regulation by TCDD involves the AhR. A. HepG2 cells were treated for $30 \mathrm{H}$ with either $25 \mathrm{nM}$ TCDD, $5 \mu \mathrm{M}$ benzo(a)pyrene $(\mathrm{BaP})$ or the vehicle $(0.15 \% \mathrm{DMSO})$. Proteins were analyzed by Western blot (anti-AGR2 monoclonal antibody). A. A typical western blot is shown. Intensities were normalized by comparison to the actin signal (3 separate experiments). There was a significant increase (Fisher-test) in AGR2 protein following treatment with TCDD and B(a)P $(* * P<0.001)$. B. Left. siRNAs (control or AhR) were transiently transfected into HepG2 cells using the HiPerfect reagent. After $16 \mathrm{H}$, the cells were treated, or not, with $25 \mathrm{nM}$ TCDD for $30 \mathrm{H}$. The AGR2 mRNA level was measured by qRT-PCR. The mean fold increase \pm SEM as compared to the control for 4 independent experiments performed in duplicate is shown. Statistical analysis (Fisher-test) showed that the TCDD induced increase in AGR2 mRNA was significantly decreased with the two siAhR RNAs as compared to the control siRNA (* $P<0.05, * * * P<0.0001)$. Right. Western blots of the AhR and AGR2 protein amount in HepG2 cells transfected with either control siRNA or AhR siRNA and treated or not with $25 \mathrm{nM}$ TCDD is shown.Actin is shown as a control.

Figure 4. Half-life of AGR2 mRNA in HepG2 cells. HepG2 cells were pretreated for 30H 
with either $25 \mathrm{nM}$ TCDD or the vehicle $(0.15 \% \mathrm{DMSO})$. Then, the cells were treated, or not, with $10 \mu \mathrm{M}$ DRB and mRNA was isolated as a function of time. The AGR2 mRNA level was assessed by qRT-PCR. The statistical analysis (Fisher-test) showed no statistically significant difference in the half-life of AGR2 mRNA in cells treated, or not, by TCDD in the presence of DRB (6 experiments performed in duplicate).

Figure 5. TCDD increases AGR2 gene promoter activity. A. AGR2 gene promoter constructs (wild type or mutated in the XRE) in front of the Gaussia luciferase were transiently transfected into HepG2 cells which were treated, or not, with $25 \mathrm{nM}$ TCDD for 30H. The reporter activity was expressed in arbitrary units. There was a statistically significant (Fisher-test) difference in reporter activity between treated and untreated cells $(* *$ $P<0.001, \quad * * * \quad P<0.0001,3$ to 19 experiments for each construct). B. Chromatin immunoprecipitation experiment carried out on the AGR2 promoter XRE1 region. HepG2 cells were treated, or not, with $25 \mathrm{nM}$ for $45 \mathrm{~min}$. Gene specific qPCR analysis with primers spanning the AhR-binding region in the AGR2 gene promoter was performed on genomic DNA immunoprecipitated with either anti-AhR or mock IgG antibody and an equal amount of input DNA as described in the methods. The non-treated sample was used as control for each condition. (*** $P<0.0001,3$ experiments) (right). The electrophoretic mobility shift assay shows the binding of nuclear extracts prepared from TCDD-treated HepG2 cells $(25 \mathrm{nM}, 90$ min) to a probe encompassing the XRE1 (lane2), after competition with an anti-AhR antibody (lane3) and after competition with a 50X non labeled probe (lane 4). Lane 1 corresponds to the free probe. C. The longest wild type construct (-3401/+8 AGR2) transiently transfected into HepG2 cells was treated with $0.15 \%$ DMSO or increasing TCDD concentrations for $30 \mathrm{H}$ or $5 \mu \mathrm{M} \mathrm{B}(\mathrm{a}) \mathrm{P}$. The reporter activity is expressed in arbitrary units. There was a statistically significant (Fisher-test) difference in reporter activity between treated and untreated cells at 
concentrations above $1 \mathrm{nM}$ TCDD (** $P<0.001,{ }^{* * *} P<0.0001,3$ to 5 experiments).

Figure 6. TCDD attenuates the phosphorylation and the acetylation of $p 53$ and the caspases 3/7 activities elicited by etoposide via AGR2. HepG2 cells transfected by either control siRNA or siRNA directed against AGR2 were pre-treated with either $0.15 \%$ DMSO or $25 \mathrm{nM}$ TCCD for $24 \mathrm{H}$ and incubated, or not, with 15 or $75 \mu \mathrm{M}$ etoposide for an additional 24H. A. Protein extracts were analyzed by Western blot. Phosphorylated and acetylated p53 and AGR2 were measured with specific antibodies. B. Intensities on Western blots were normalized as compared to the actin signal ( 3 to 5 separate experiments). There was a statistically significant decrease in p53 levels when the cells tranfected by the control siRNA were treated with etoposide and TCDD as compared to etoposide alone ( ${ }^{*} P<0.04$ and $P<0.02$ for phosphorylated and acetylated p53, respectively, Fisher test) whereas no difference was observed when the cells were transfected by AGR2 si RNA. C. HepG2 cells transfected by either control siRNA or siRNA directed against AGR2 were pre-treated with either $0.15 \%$ DMSO or $25 \mathrm{nM}$ TCCD for $24 \mathrm{H}$ and incubated, or not, with $75 \mu \mathrm{M}$ etoposide for an additional $24 \mathrm{H}$. Caspases 3/7 activities were measured as described in the Methods. There was a statistically significant increase (Fisher-test) in activity following etoposide and etoposide plus TCDD treatments as compared to DMSO. However, the increase with the mixture of etoposide plus TCDD was significantly less than with etoposide alone when control siRNA was used (Fisher-test) whereas with AGR2 siRNA there was no difference between the mixture of etoposide plus TCDD and etoposide alone (** $P<0.001$; *** $P<0.0001)$.

Figure 7. Schematic model for the role of AGR2 expression in the inhibition by TCDD of etoposide elicited p53 and caspases $3 / 7$ activation. Results from the literature are shown in dotted lines. 
Figure 1A
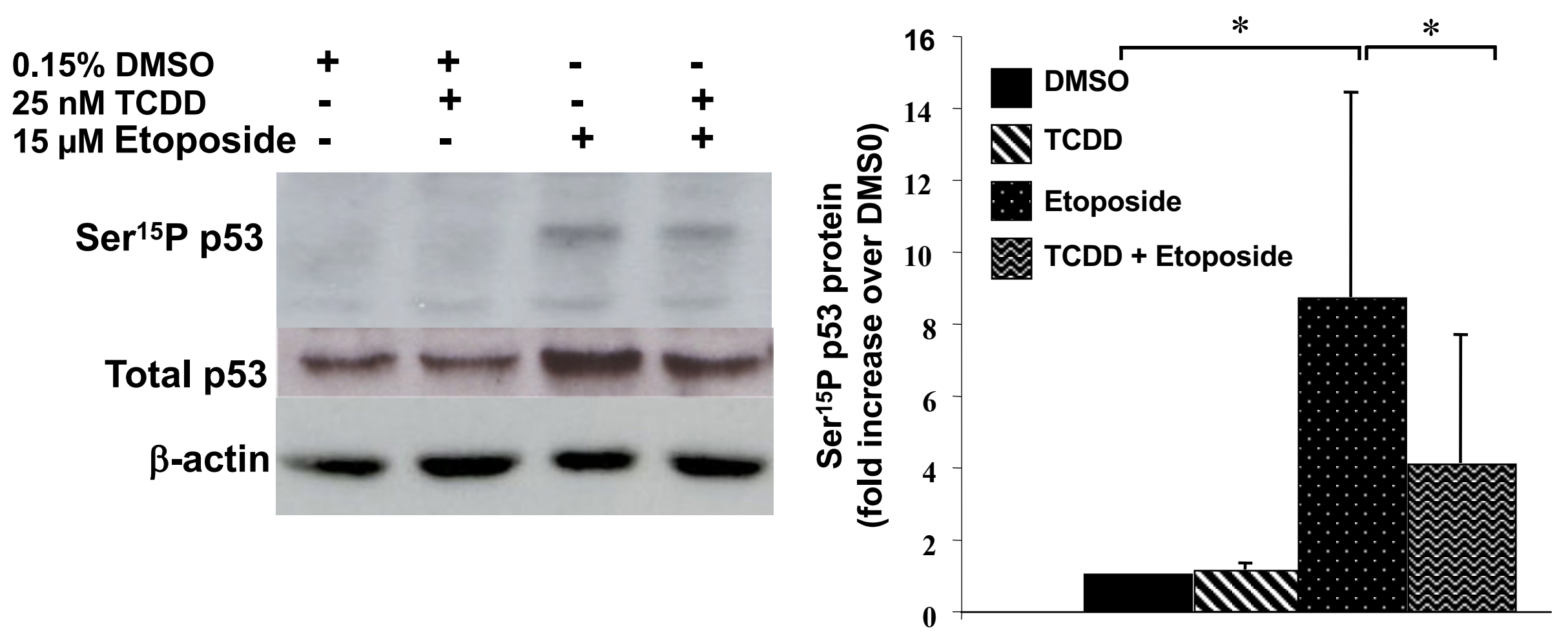
Figure 1B

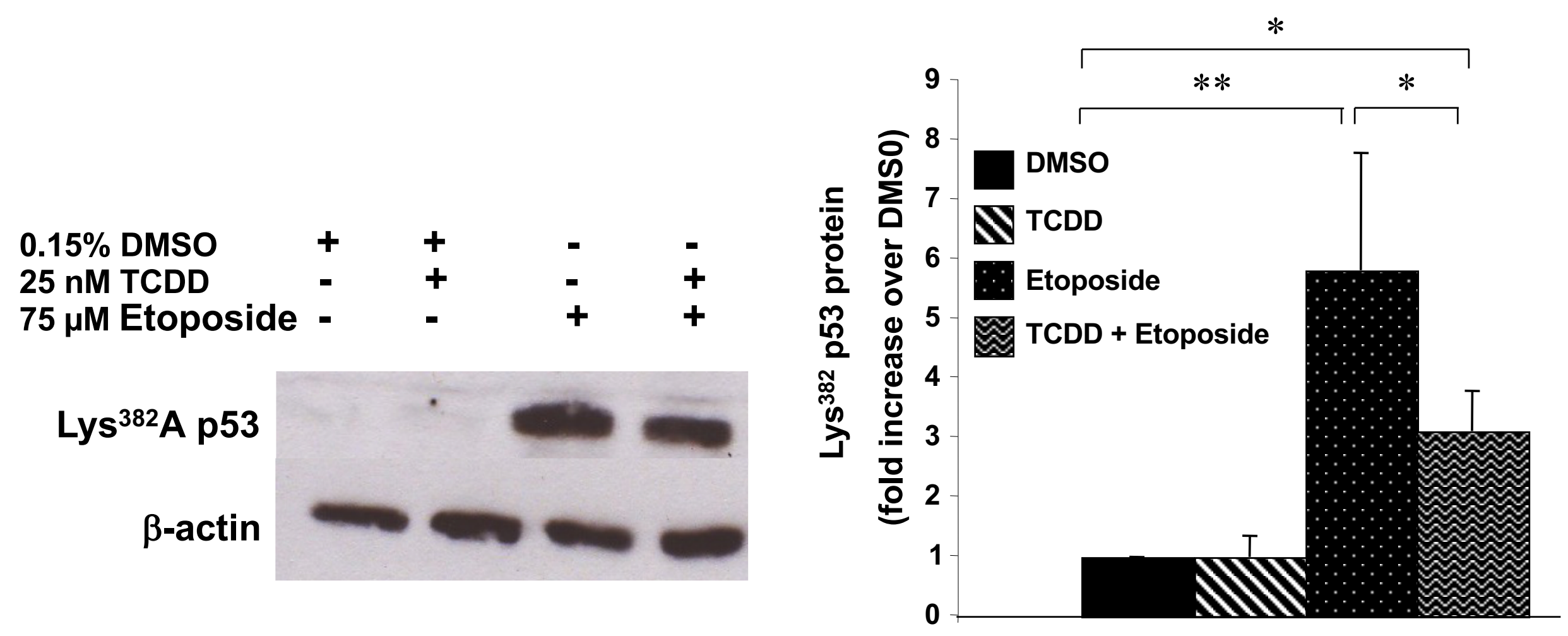


Figure 1C

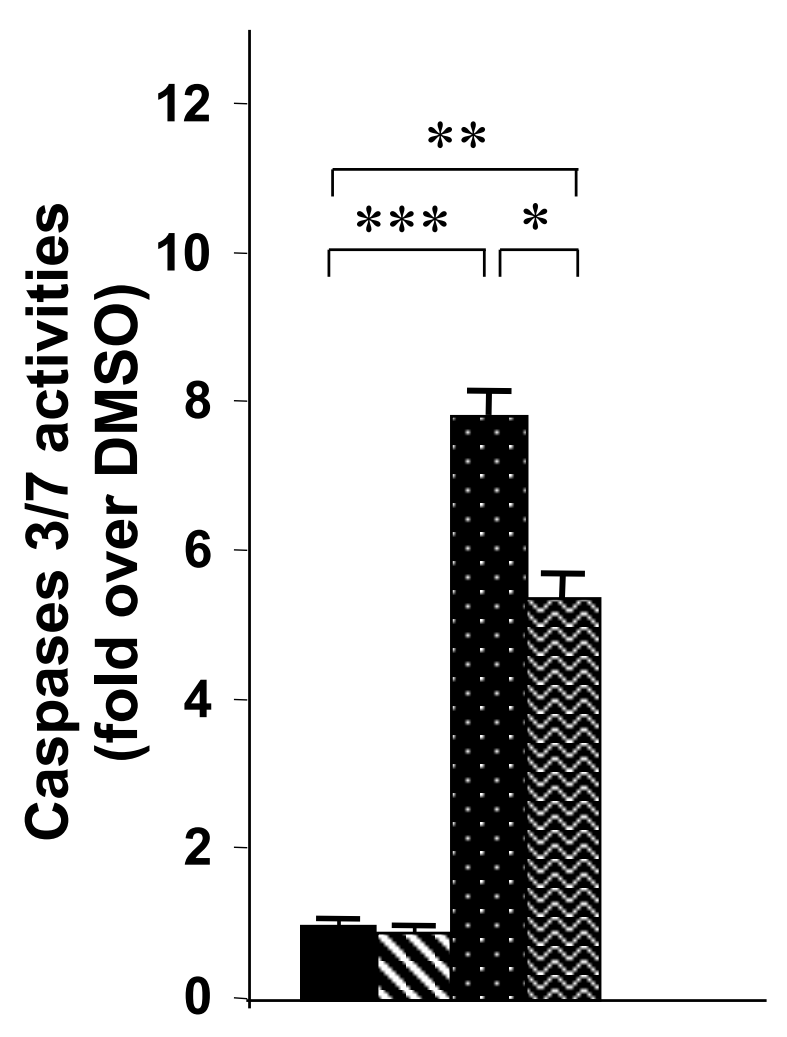


Figure 2A

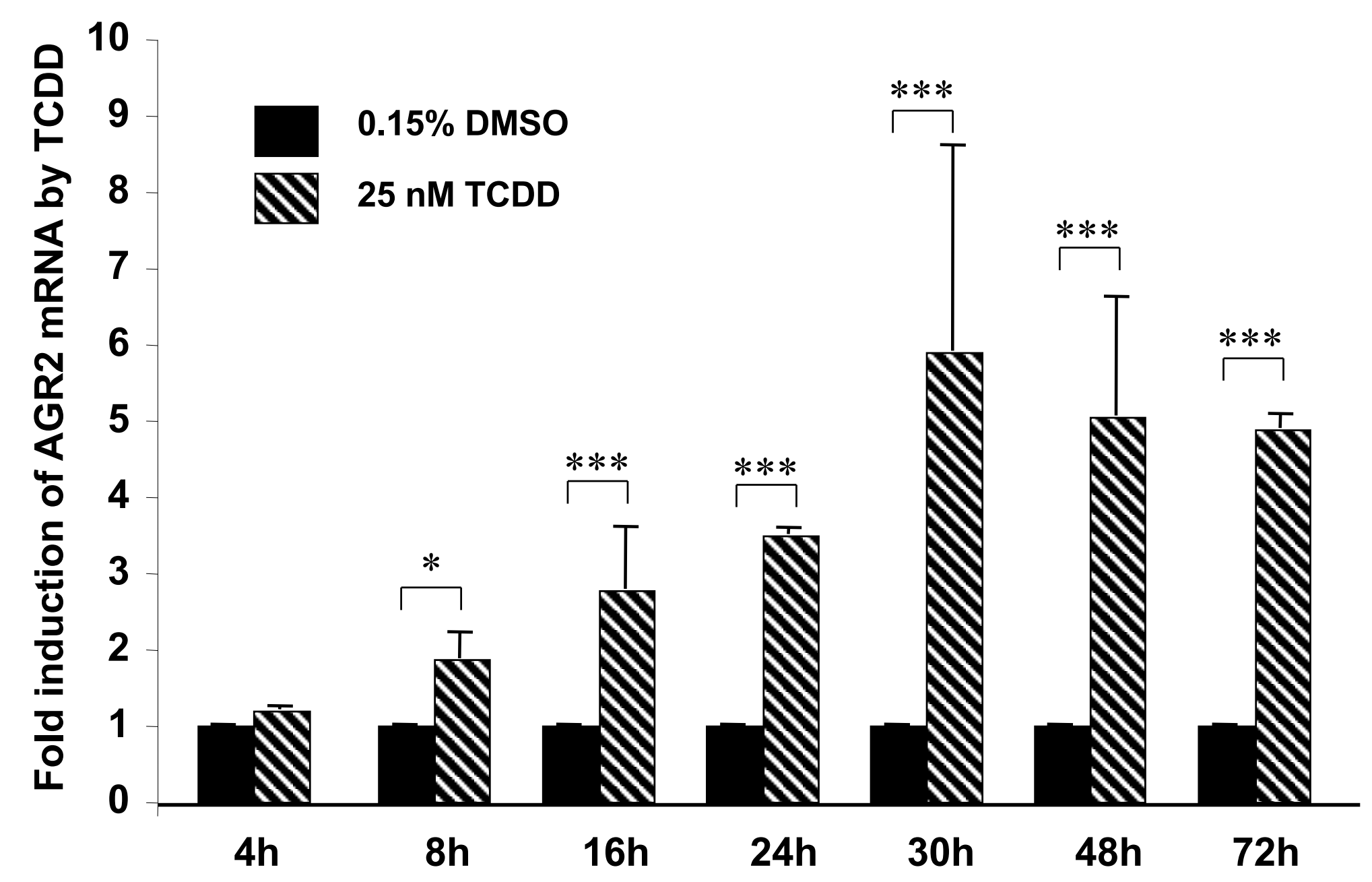


Figure 2B

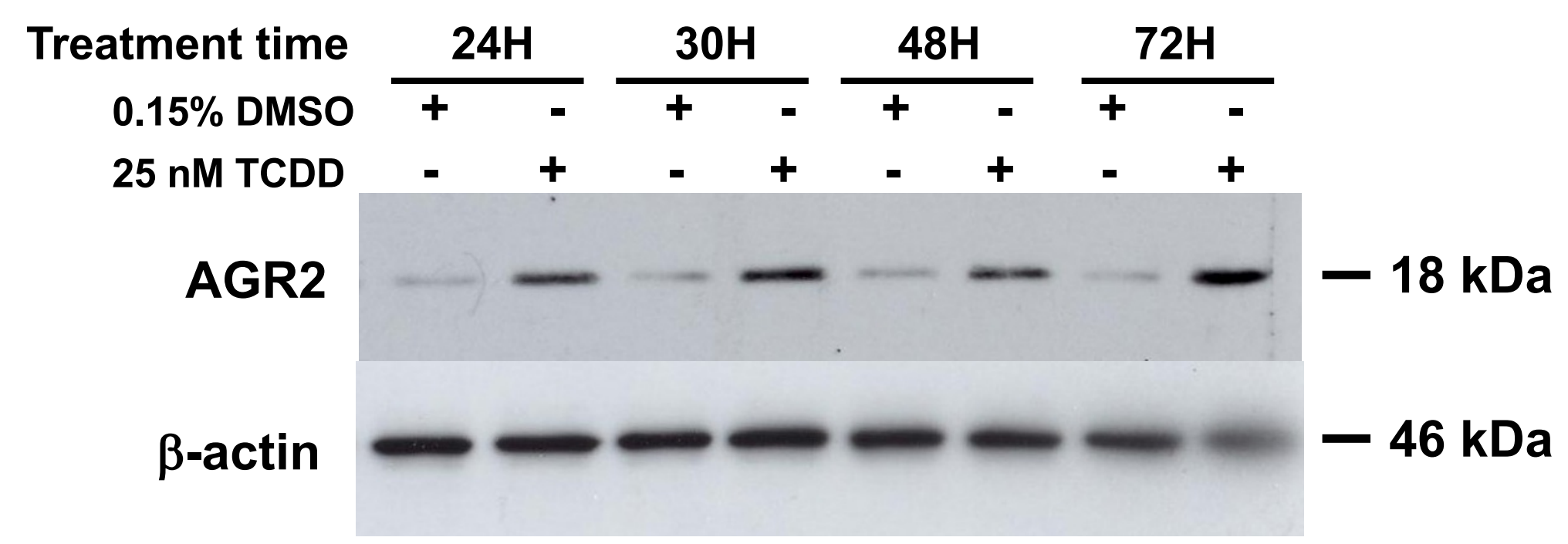


Figure 2C

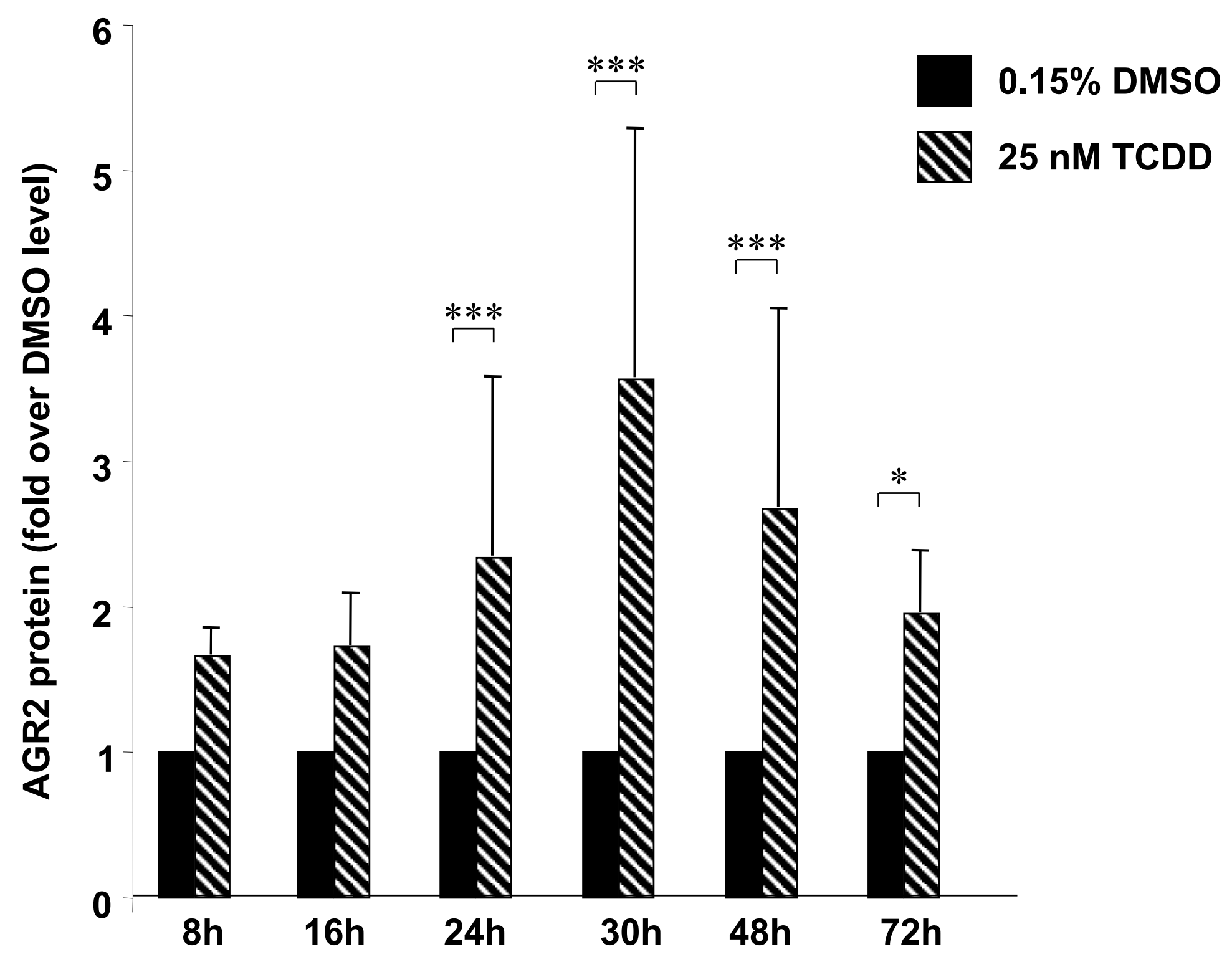


Figure $3 \mathrm{~A}$

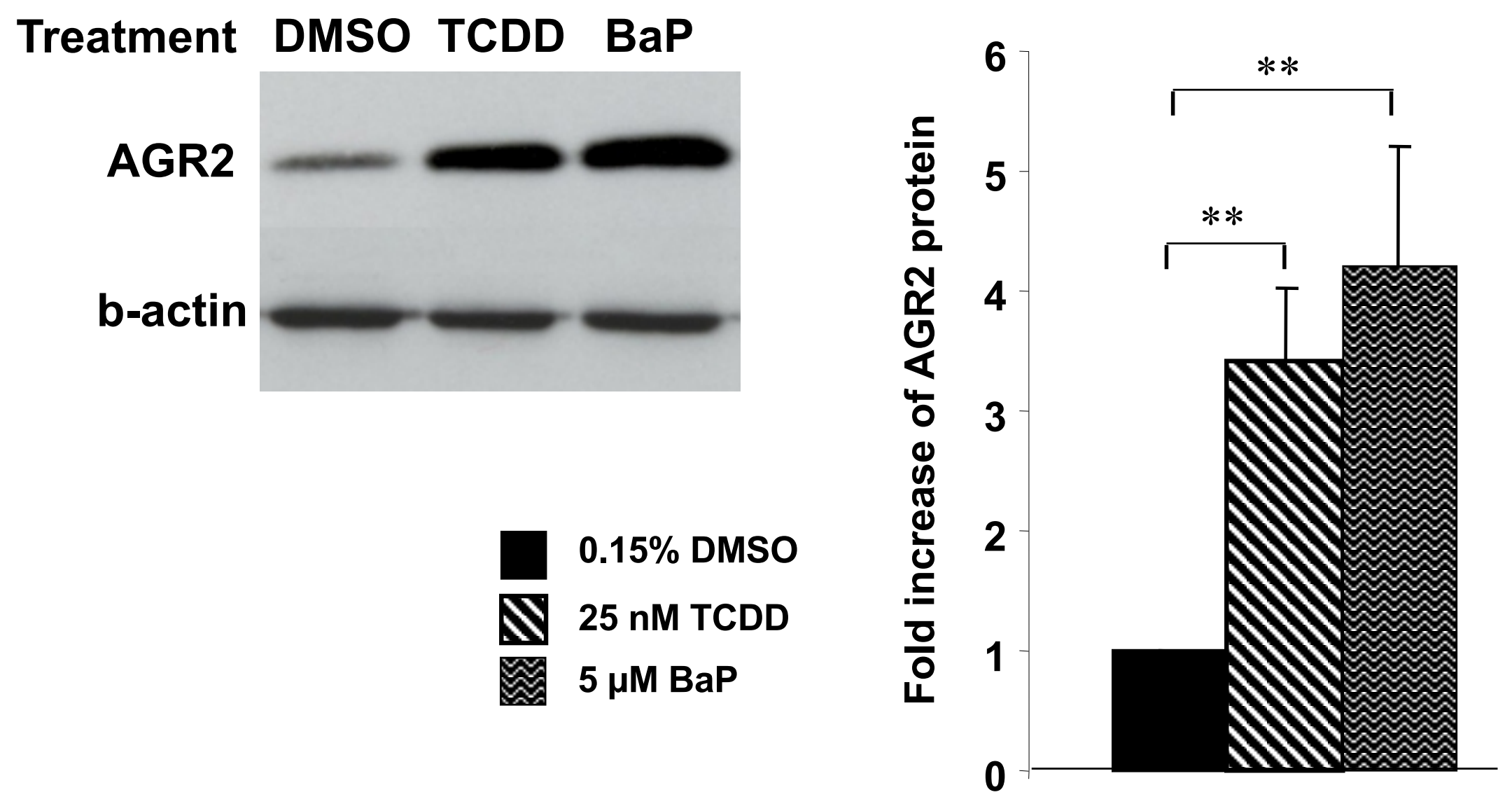


Figure 3B

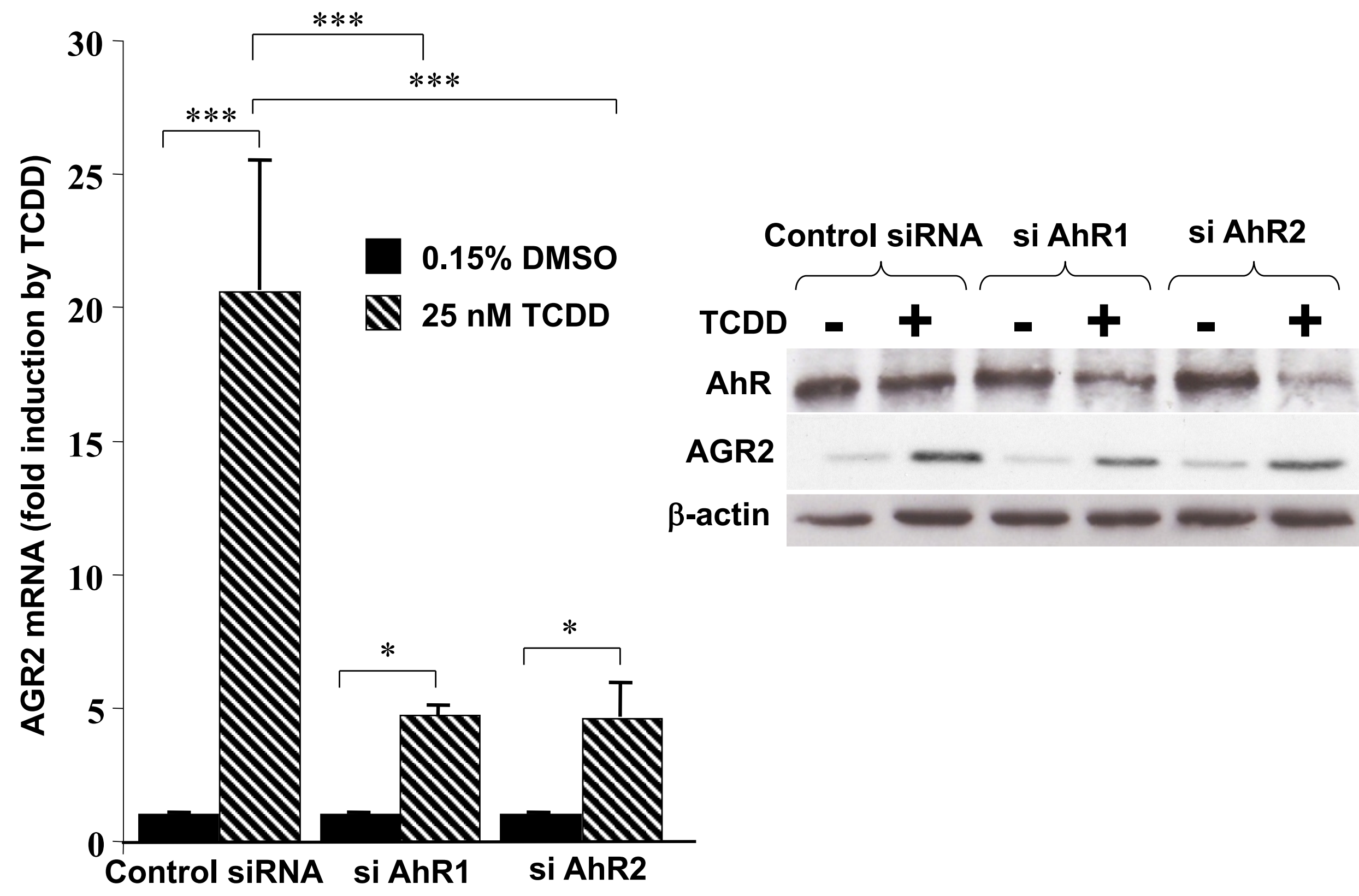




\section{Figure 4}

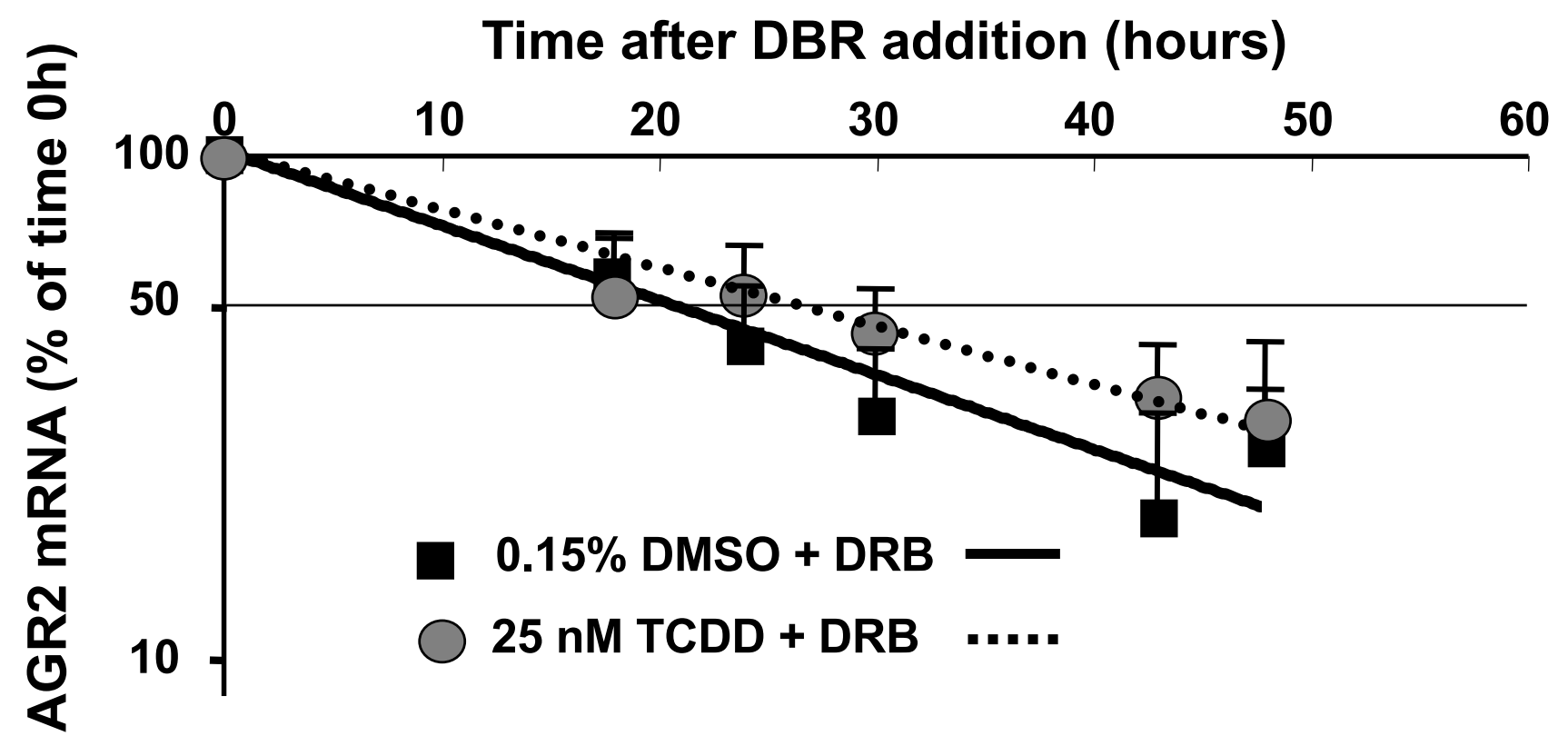


Figure 5A

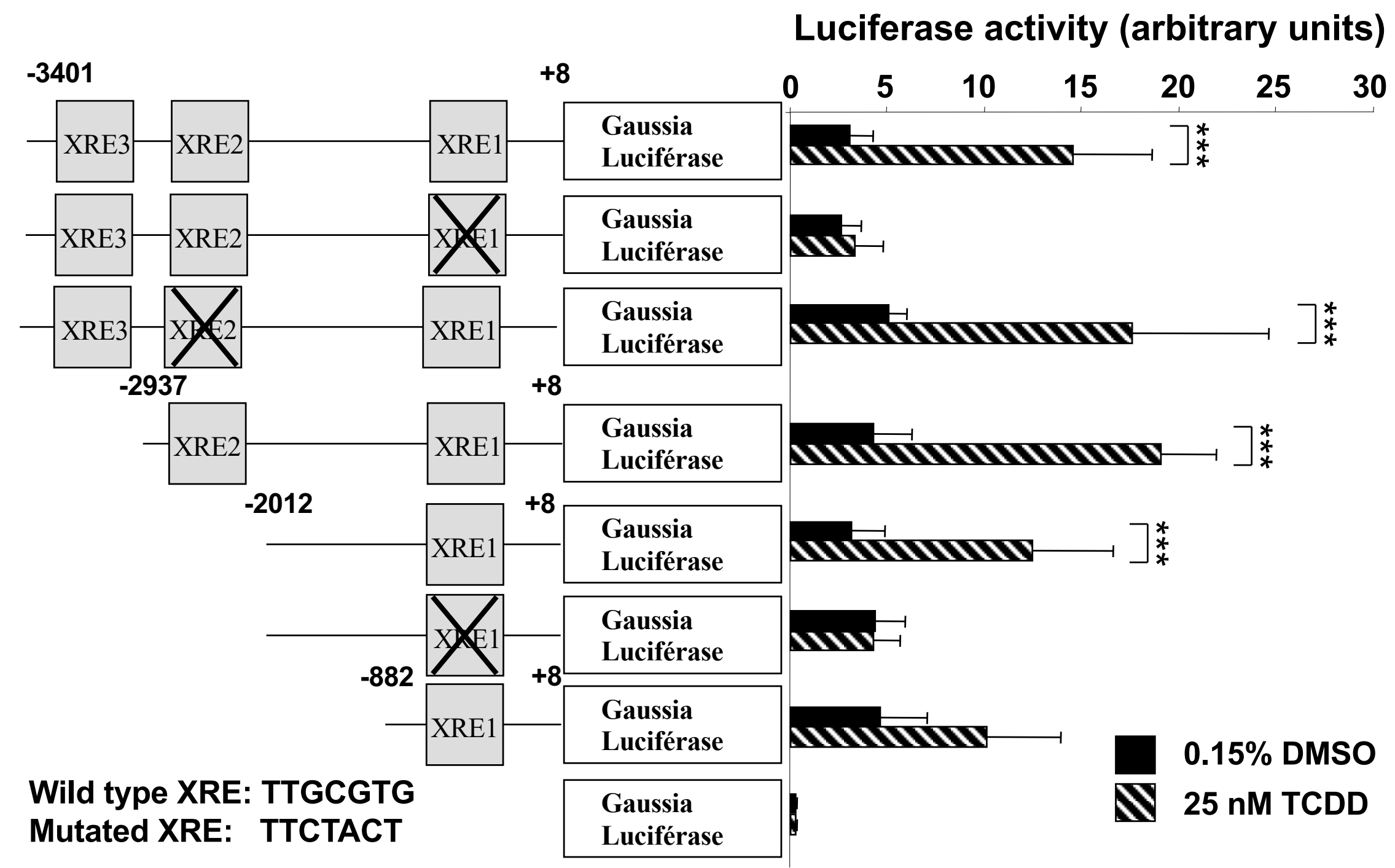


Figure 5B
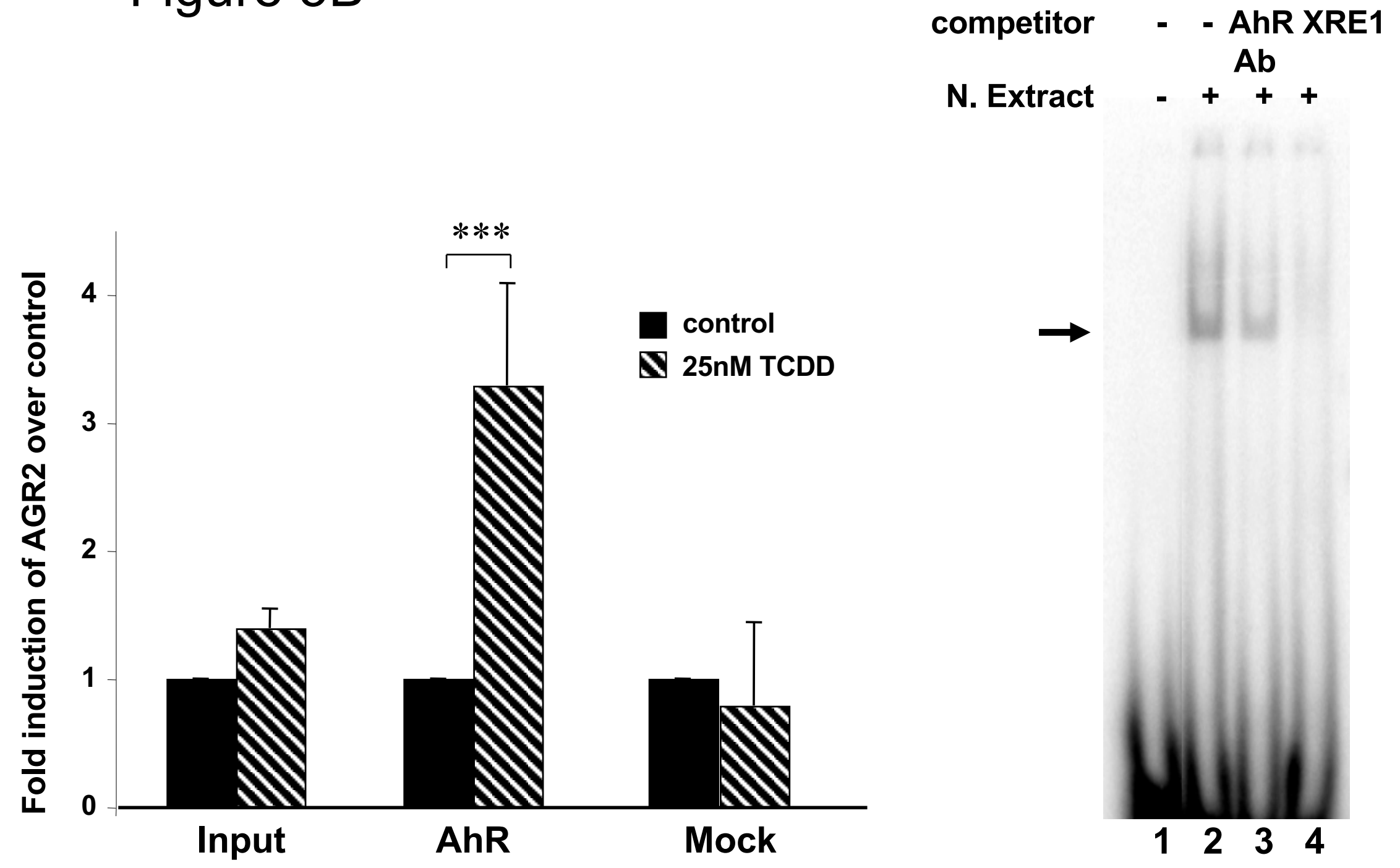

N. Extract $\quad-\quad++$

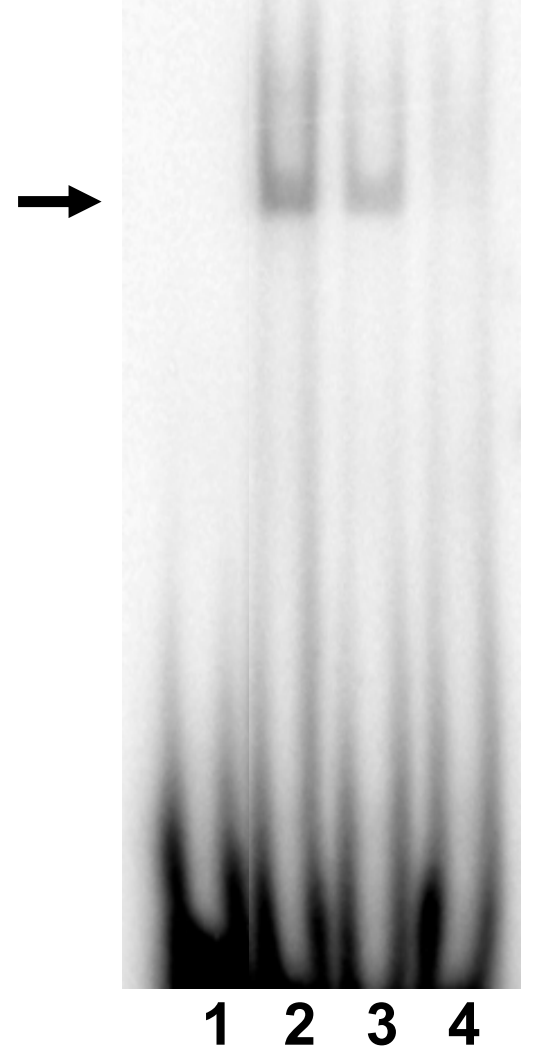


Figure 5C

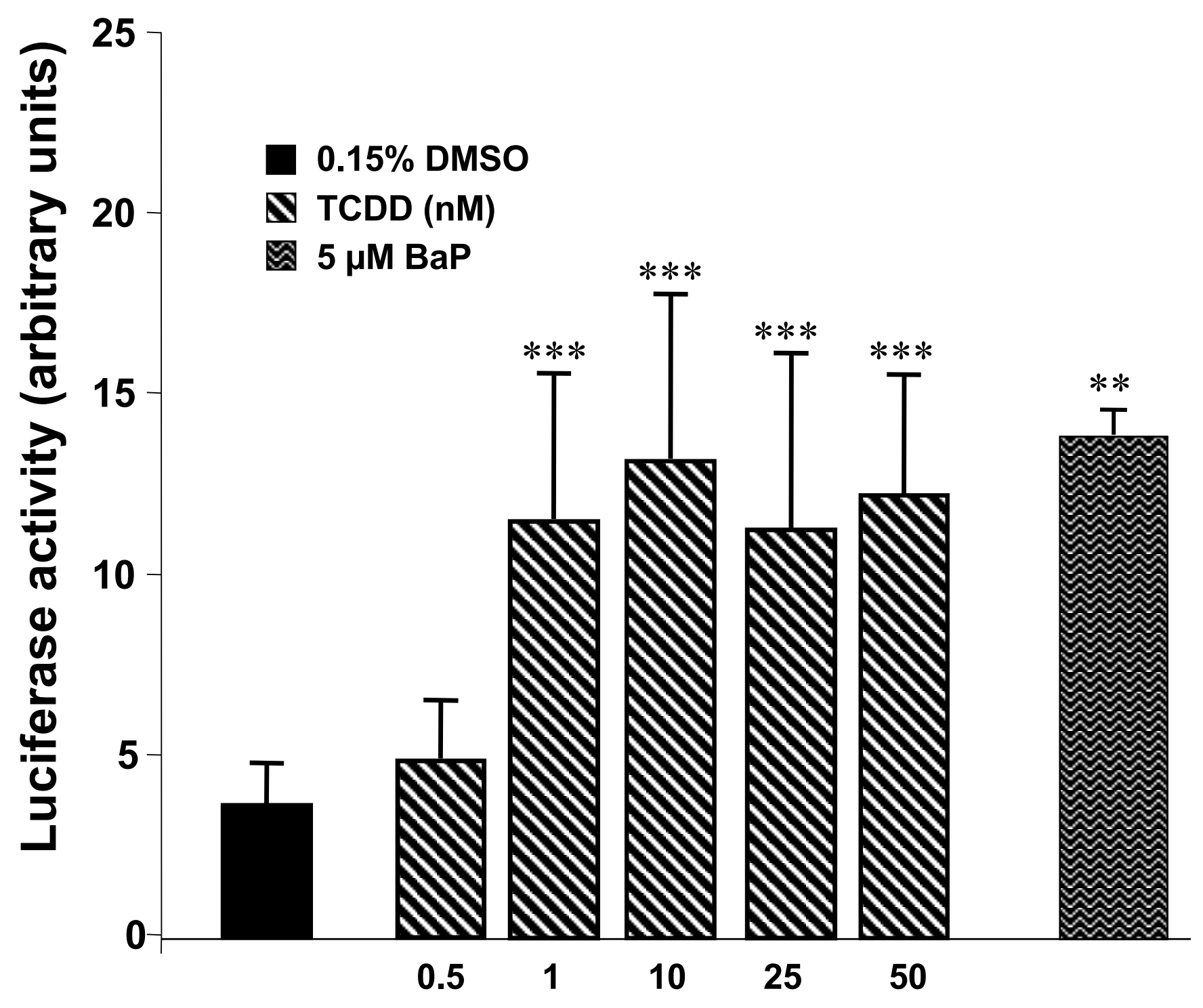


Figure 6A

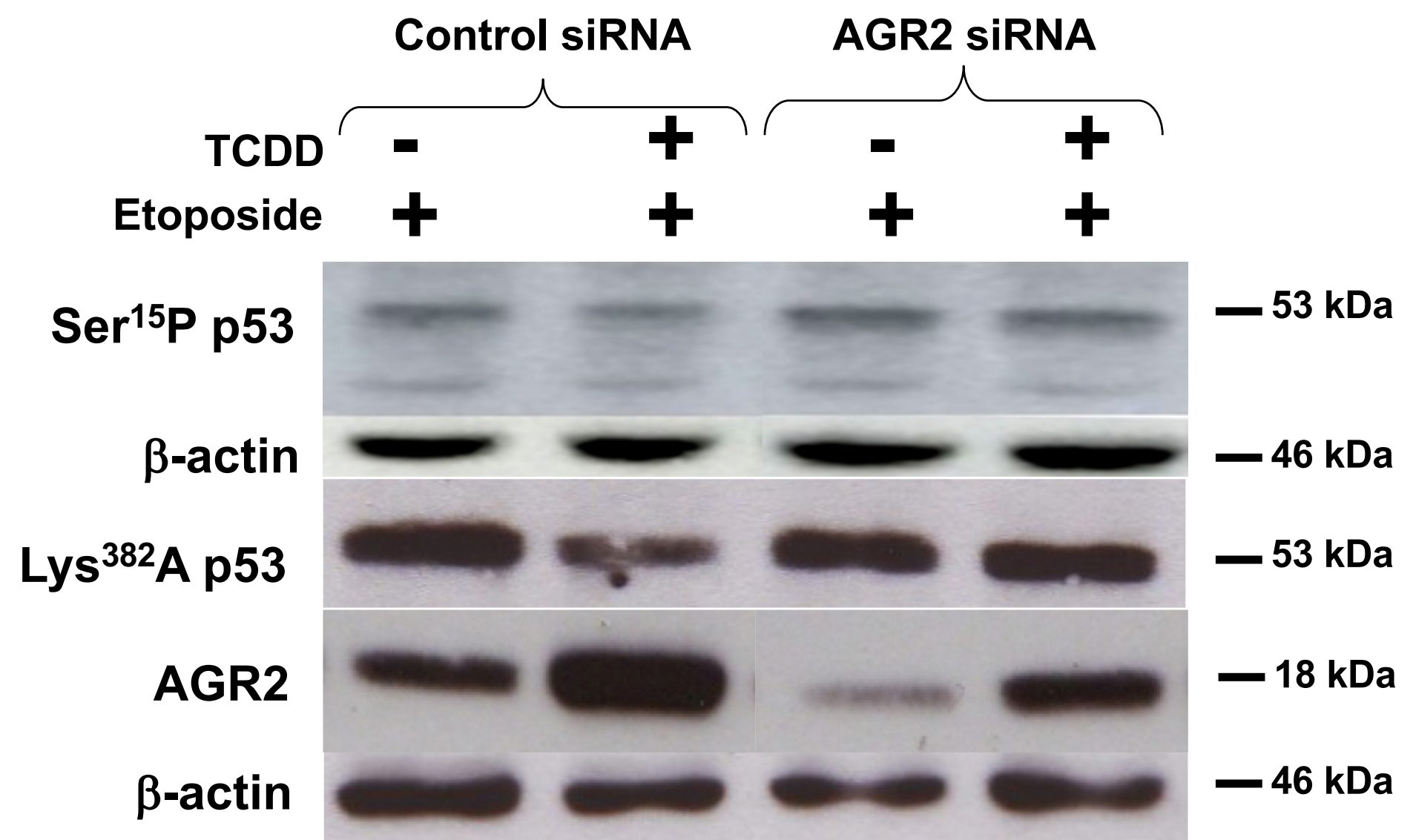


Figure 6B
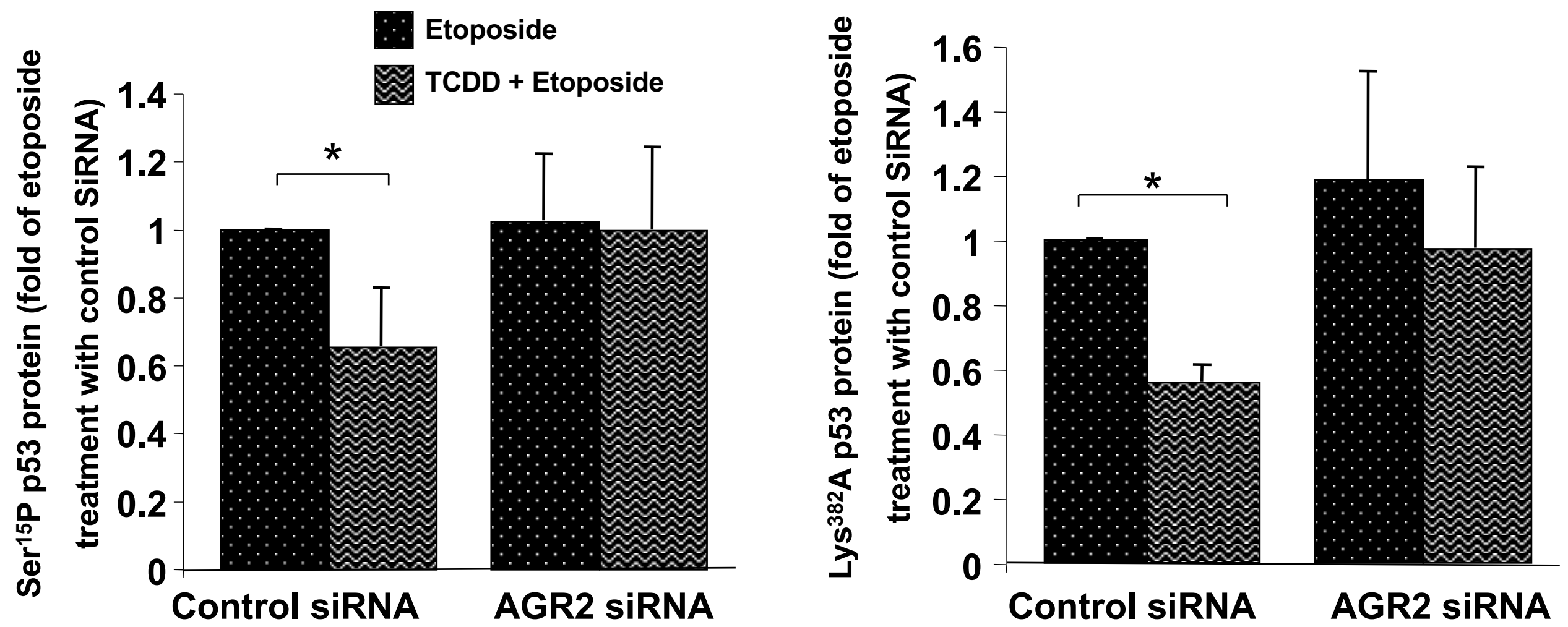
Figure 6C

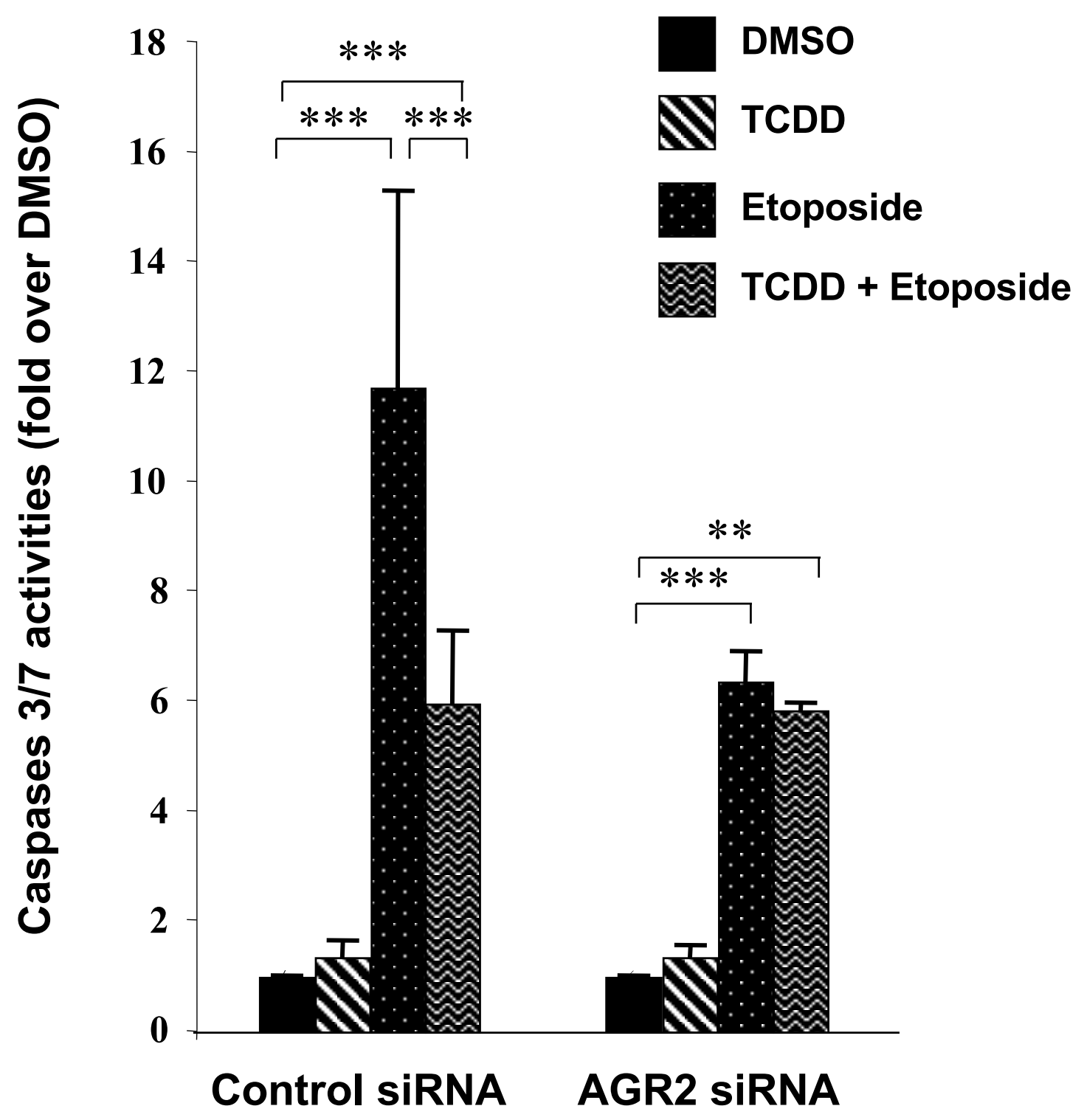


Figure 7
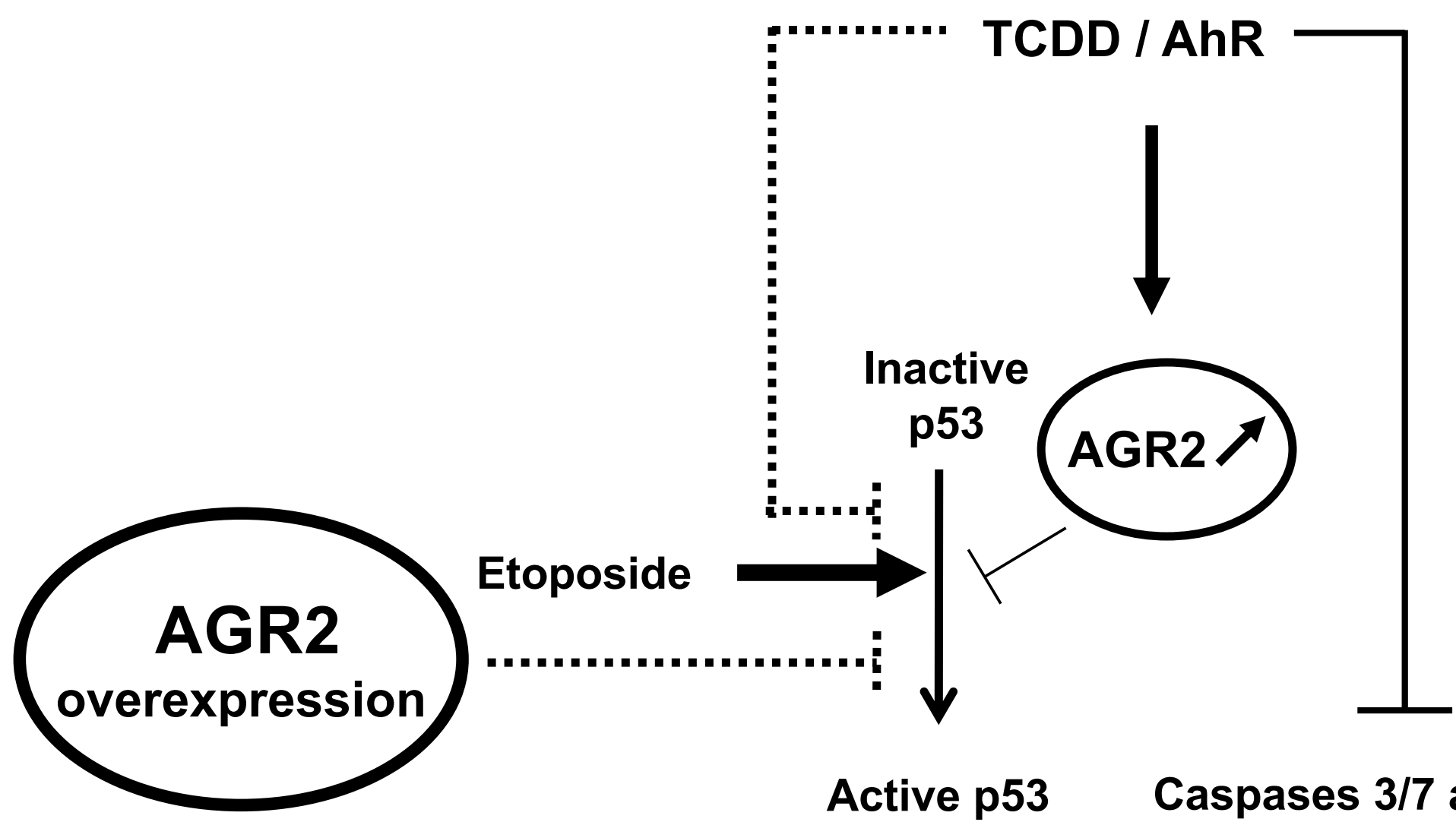

Active p53 Caspases 3/7 activation by etoposide 
Figure 7
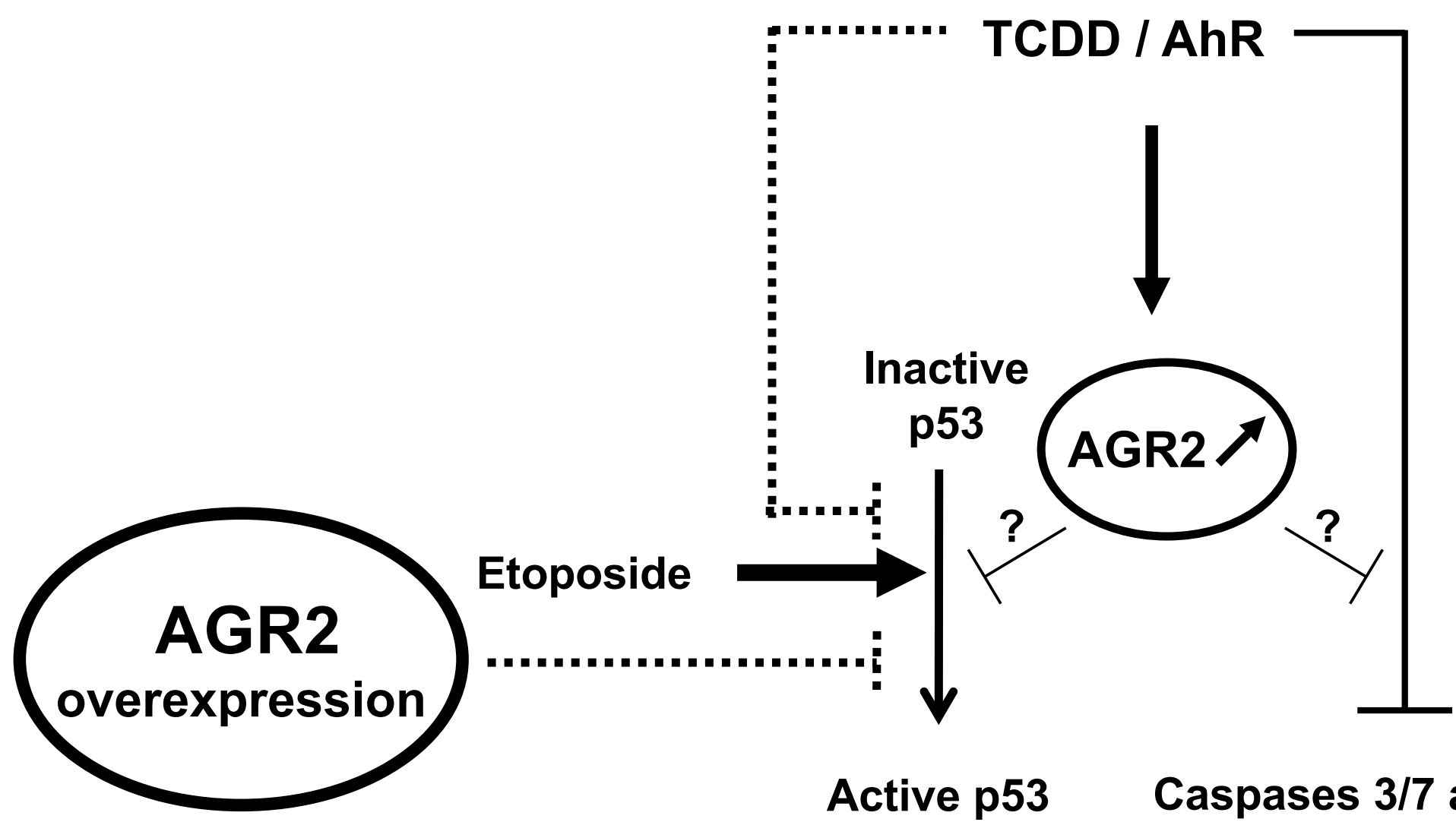

Active p53 Caspases 3/7 activation by etoposide 